\title{
Tetralogy of Fallot with Restrictive Ventricular Septal Defect
}

\author{
Ashish Tiwari $^{1}$ (D) Savita Bhunwal ${ }^{2} \cdot$ Manojkumar Rohit $^{1}$
}

Received: 11 July 2017 / Accepted: 20 September 2017 / Published online: 20 November 2017

(C) Dr. K C Chaudhuri Foundation 2017

To the Editor: Tetralogy of Fallot (TOF) is the most common congenital cyanotic heart disease after first year of life. Ventricular septal defect is usually unrestricted and malaligned. Main purpose of this communication is to present an uncommon case of TOF with heart failure due to restrictive VSD caused by ventricular septum hypertrophy.

A 6-y-old boy was referred to us with features of right heart failure, complaints of cyanosis since 6 mo of age and exertional dyspnea since 5 y of age. Child was managed initially with bed rest, humidified oxygen and low dose decongestive measures. Transthoracic echocardiography was diagnostic of TOF (tetralogy of fallot) with a small restrictive perimembranous VSD (ventricular septal defect) with hypertrophy of ventricular septum causing restriction with mild aortic regurgitation (Fig. 1). After initial stabilization, patient was operated and discharged successfully on post-operative day 12 .

In TOF, VSD is usually nonrestrictive. TOF with restrictive VSD is a rare entity and is one of the rarest cause of congestive cardiac failure in TOF. Cause for the restriction of VSD can be accessory tricuspid valve tissue, tricuspid valve vegetation, prolapsed aortic valve and membranous flap and very rarely, caused by hypertrophied ventricular septum. Very limited literature is available on septal hypertrophy as the cause for restriction of VSD [1, 2]. One such case was described by Flanagan et al. in 1988 where restriction of VSD was caused by hypertrophied ventricular septum in one pediatric patient [1]. Table 1 summarizes the causes of heart failure in TOF. In conclusion, TOF is rarely associated with restrictive VSD and it is a cause for suprasystemic right ventricular pressure and subsequent right heart failure.

Ashish Tiwari

aashishtiwari@live.com

1 Department of Cardiology, Advance Cardiac Center, PGIMER, Chandigarh 160012, India

2 Department of Pediatrics, Advance Pediatric Center, PGIMER, Chandigarh, India

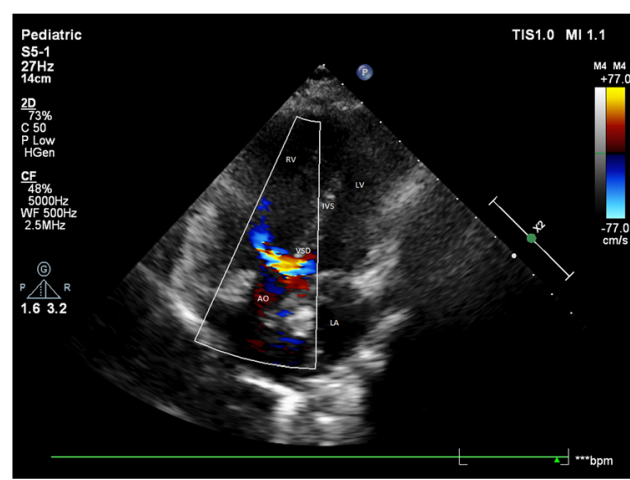

Fig. 1 Echocardiography showing restrictive VSD

Table 1 Causes of CCF in TOF

1. Anemia

2. Large aortopulmonary collaterals

3. Oversize BT (Blalock-Taussig) shunt surgery

4. Restrictive VSD with suprasystemic RV pressures

5. Infective endocarditis

6. Incidental myocarditis

. Aortic regurgitation

. Systemic hypertension

9. Coronary artery disease

VSD Ventricular septal defect; $R V$ Right ventricular

Compliance with Ethical Standards

Conflict of Interest None.

Source of Funding None.

\section{References}

1. Flanagan MF, Foran RB, VanPraagh R, Jonas R, Sanders SP. Tetralogy of Fallot with obstruction of the ventricular septal defect: spectrum of echocardiographic findings. J Am Coll Cardiol. 1988;11:386-95.

2. Faggian G, Frescura C, Thiene G, Bortolotti U, Mazzucco A, Anderson RH. Accessory tricuspid valve tissue causing obstruction of the ventricular septal defect tetralogy of Fallot. Br Heart J. 1983;49:324-7. 